\title{
Microstructural evolution and mechanical properties of hypereutectic Al-Si alloy processed by liquid die forging
}

\author{
F F WU*, S T LI, G A ZHANG and F JIANG \\ School of Materials Science and Engineering, Liaoning University of Technology, Jinzhou 121001, China
}

MS received 6 July 2013; revised 7 October 2013

\begin{abstract}
The microstructural evolution and mechanical properties of a hypereutectic Al-Si alloy processed by liquid die forging were investigated. It is found that the grain size of the primary Si was significantly reduced by liquid die forging with increased pressure. The volume fraction of eutectic silicon was decreased with increased pressure. By liquid die forging with pressure up to $180 \mathrm{MPa}$, the average size of the primary Si was reduced to about $18 \mu \mathrm{m}$, which results in the remarkable increase in the fracture strength and hardness of the hypereutectic Al-Si alloy.
\end{abstract}

Keywords. Mechanical properties; hypereutectic Al-Si alloy; liquid die forging.

\section{Introduction}

Hypereutectic Al-Si alloys possess attractive properties, such as low specific gravity, high strength at elevated temperature, excellent resistance and low coefficient of thermal expansion (Mohamed et al 2009; HekmatArdakan and Ajersch 2010; Sha et al 2012). Therefore, they are attractive candidate materials for automotive, aerospace and electronics fields, especially, where the alloys substitute for cast iron, when the engineering advantages of light weight and wear resistance are considered (Hekmat-Ardakan et al 2010; Choi and Li 2012).

Usually, the microstructure of hypereutectic Al-Si alloys is composed of the primary $\mathrm{Si}$ crystals and the eutectic mixture of $\alpha$-Al and eutectic Si. The size, morphology and distribution of the primary and eutectic Si play important roles in determining the mechanical properties and wear behaviours of the hypereutectic Al$\mathrm{Si}$ alloys. However, by conventional casting processes, the primary $\mathrm{Si}$ crystals exist in the shape of star-like, polygonal, plate-like and feathery shape, and the eutectic $\mathrm{Si}$ is coarse and acicular, which is prone to premature crack initiation and fracture under tension and severely deteriorates the mechanical properties of hypereutectic Al-Si alloys (Yi and Zhang 2003). Generally, fine, spherical and uniformly distributed primary and eutectic Si crystals can improve the mechanical properties and tribological properties of hypereutectic Al-Si alloys (Liu et al 2011). Therefore, many efforts have been made to investigate the refinement and the morphological evolution of the primary and eutectic Si phases in Al-Si alloys

*Author for correspondence (ffwoo@foxmail.com) such as adding modifiers (Dahle et al 2005), semi-solid processing (Jung et al 2001), superheating treatment of the melt (Chen et al 2005), electromagnetic field treatment (Lu et al 2007) and quench modification (Uzun et al 2004; Song et al 2007; Wang et al 2011). Chemical elements such as $\mathrm{Sr}, \mathrm{Na}, \mathrm{Ce}, \mathrm{Sc}, \mathrm{La}, \mathrm{Y}, \mathrm{Yb}$ and $\mathrm{Er}$ (McDonald et al 2004; Lu et al 2005; Prukkanona et al 2009; Tsai et al 2009; Nogita et al 2010; Xing et al 2010a; Li et al 2011a, b; Srirangam et al 2011; Vončina et al 2011) can effectively change the morphology of the eutectic Si from coarse needle- or flake-like to fine coral structure. Meanwhile, some studies proved that the primary $\mathrm{Si}$ of hypereutectic Al-Si alloys can be successfully refined by adding red phosphorus, phosphate salt, Al-P or $\mathrm{Cu}-\mathrm{P}$ master alloys to form AlP particles as the nucleation agents for primary $\mathrm{Si}$ crystals (Wang et al 2009). Misch metals, such as Sc, Er and Ce can also significantly refine the primary $\mathrm{Si}$ in hypereutectic $\mathrm{Al}-\mathrm{Si}$ alloys (Chang et al 1998; Zhang et al 2006; Xing et al 2010b; Kilicaslana et al 2012).

However, processed by adding modifier, the grain size of the primary Si crystals can only be reduced to be about $50 \mu \mathrm{m}$, which is not fine enough for enhancing the performance of hypereutectic Al-Si alloys. Therefore, it is still necessary to further refine the primary $\mathrm{Si}$ in hypereutectic Al-Si alloys by combining the modification and other processing techniques. Liquid die forging will be a potential candidate for these techniques. In liquid die forging, the high pressure (several hundred $\mathrm{MPa}$ ) can cause a high coefficient of heat transfer and nonequilibrium solidification (Wu and Chin 1991; Murali and Yong 2010). It is a hybrid of conventional casting and forging technique, which combines economics and shape capability of castings with the strength and confidence level of forging 
(Murali and Yong 2010). Casting under forging pressure can results in pore free and fine microstructures with superior mechanical properties (Begg 1992). Therefore, liquid die forging should be an effective method for producing hypereutectic Al-Si alloys with fine microstructure and excellent mechanical properties. In the present work, liquid die forging is applied to treat a hypereutectic Al-Si alloy, and the microstructural evolution and mechanical properties are investigated.

\section{Experimental}

The selected hypereutectic Al-Si alloy has a nominal chemical composition of Si (18 wt $\%), \mathrm{Cu}(4.5 \mathrm{wt} \%), \mathrm{Mn}$ $(0.1 \mathrm{wt} \%), \mathrm{Mg}(0.65 \mathrm{wt} \%), \mathrm{Zn}(0.1 \mathrm{wt} \%), \mathrm{Ti}(0.2 \mathrm{wt} \%)$ and Al (balance). All pure metals or master alloys were melted in a resistance furnace. $\mathrm{P}-\mathrm{RE}-\mathrm{Sr}$ ( $\mathrm{RE}$ is a Ce-rich rare-earth alloy) combined modifier was added to the melt to refine the primary and eutectic Si: first, 0.8\% Al$3.5 \mathrm{P}$ was added at the temperature of $1098 \mathrm{~K}$ and the temperature was held for $20 \mathrm{~min}$; second, 3\% Al-10RE was added at $1098 \mathrm{~K}$ and the temperature was held for $10 \mathrm{~min}$; third, the temperature was decreased to $1033 \mathrm{~K}$ and then $0.5 \% \mathrm{Al}-10 \mathrm{Sr}$ was added and the temperature was held for $30 \mathrm{~min}$; finally, the melt was finally held at $1093 \mathrm{~K}$ for casting. The liquid die forging was conducted in a commercial hydrostatic machine with specified load of $3 \mathrm{MN}$. The mould was made of $40 \mathrm{Cr}$ steel with hardness of HRC50. The puncher was made of $12 \mathrm{CrMoV}$ with hardness larger than HRC50. Before liquid die forging, the mould was held at $513 \mathrm{~K}$ and the melt was finally held at $1093 \mathrm{~K}$ for casting. The forging pressure was changed from 0 to $180 \mathrm{MPa}$. The pressurization rate is $10 \mathrm{MPa} / \mathrm{s}$ and the dwell time was $60 \mathrm{~s}$. The microstructure was observed by a Zeiss optical microscope (OM) and a Hitach 3000S scanning electron microscope (SEM). The gauge dimension of the tensile sample was $\varnothing$ $8 \mathrm{~mm} \times 45 \mathrm{~mm} \quad$ (diameter $\times$ length). All mechanical tests were performed with a SANS CMT5305 testing machine at room temperature. The rate of the crosshead is $0.1 \mathrm{~mm} \mathrm{~s}^{-1}$. A extensometer was used for measuring the strain. After tests, all the samples were observed by using SEM to reveal the deformation and fracture features.

\section{Results and discussion}

\subsection{Microstructure of hypereutectic Al-Si alloy processed by liquid die forging}

Figures 1 and 2 show the microstructure evolution of hypereutectic Al-Si alloy under different liquid-die-forging pressure, which demonstrates a substantial microstructural evolution in size and morphology of the primary Si crystals. When the pressure was $0 \mathrm{MPa}$, the average grain size of the primary Si was about $42 \mu \mathrm{m}$, and the distribution of the primary and eutectic Si was very non-uniform (figure 1a). When the pressure was increased up to $110 \mathrm{MPa}$, the average size of the primary Si was reduced to about $30 \mu \mathrm{m}$ and the eutectic Si was also distributed more homogeneously (figure $1 \mathrm{~b}$ ). When the pressure was increased up to 140 and $180 \mathrm{MPa}$, the average size of the primary $\mathrm{Si}$ was decreased to be about 25 and $18 \mu \mathrm{m}$, respectively (figure $1(\mathrm{c}$ and $\mathrm{d})$ ). Meanwhile, with the liquid die-forging pressure increasing, the eutectic Si was decreased gradually, as shown in figure 1.

Both the grain size and the volume fraction of the primary Si phase decrease in the hypereutectic Al-Si alloy solidification at liquid die forging, which can be attributed to the decrease in the diffusivity and the extended solid solution under high pressure. Meanwhile, high pressure will increase the melting point for $\mathrm{Al}$ and decrease the melting point for $\mathrm{Si}$, which will change the phase diagram (Brazhkina et al 1991; Wu and Chin 1991; Yu et al 1999; $\mathrm{Li}$ et al 2012). It is measured that the melting point for $\mathrm{Al}$ increases to $6.4 \mathrm{~K}$, when the pressure enhances $100 \mathrm{MPa}$. According to Clapeyron equation (Yu et al 1999)

$$
\mathrm{d} T=\frac{T_{\mathrm{m}}\left(V_{2}-V_{1}\right)}{\Delta H_{\mathrm{m}}} \mathrm{d} P,
$$

where $\mathrm{d} P$ is the pressure change, $\mathrm{d} T$ the change of melting point with $\mathrm{d} P, T_{\mathrm{m}}$ the melting point, $V_{1}$ the volume of $1 \mathrm{~kg}$ solid alloy, $V_{2}$ the volume of $1 \mathrm{~kg}$ liquid alloy and $\Delta H_{\mathrm{m}}$ the melting latent heat. It can be calculated from (1) that the melting point for $\mathrm{Al}$ increases. But the melting point for $\mathrm{Si}$ decreases because the volume for $\mathrm{Si}$ contracts when it melts. Therefore, under high pressure, the eutectic point transfers to higher temperature and larger Si content, which decreases the volume fraction of the primary $\mathrm{Si}$ in the hypereutectic Al-Si alloy. Meanwhile, the liquid dieforging pressure can increase the supercooling of hypereutectic Al-Si melt, which leads to increase in nuclei for the primary $\mathrm{Si}$ and the refinement of the primary $\mathrm{Si}$ (Murali and Yong 2010). Meanwhile, the increased pressure can reduce the diffusion coefficient of the solute element $\mathrm{Si}$ in the melt, resulting in the homogeneous distribution of the alloying element $\mathrm{Si}$ in the melt, and increasing the supersaturation of the alloying element Si. Moreover, with the supercooling increasing, the solidification rate increased, which was beneficial to form the supersaturated solid solution (Yu et al 2000; Hong and Zeng 2002). As to the hypereutectic Al-Si alloy, with the pressure increasing, the alloy melt stayed in a supersaturated state, leading to the $\mathrm{Al}$ enrichment in front of the interface and reduction of the eutectic silicon. Therefore, with increasing pressure, both the primary and eutectic Si can be effectively refined. 

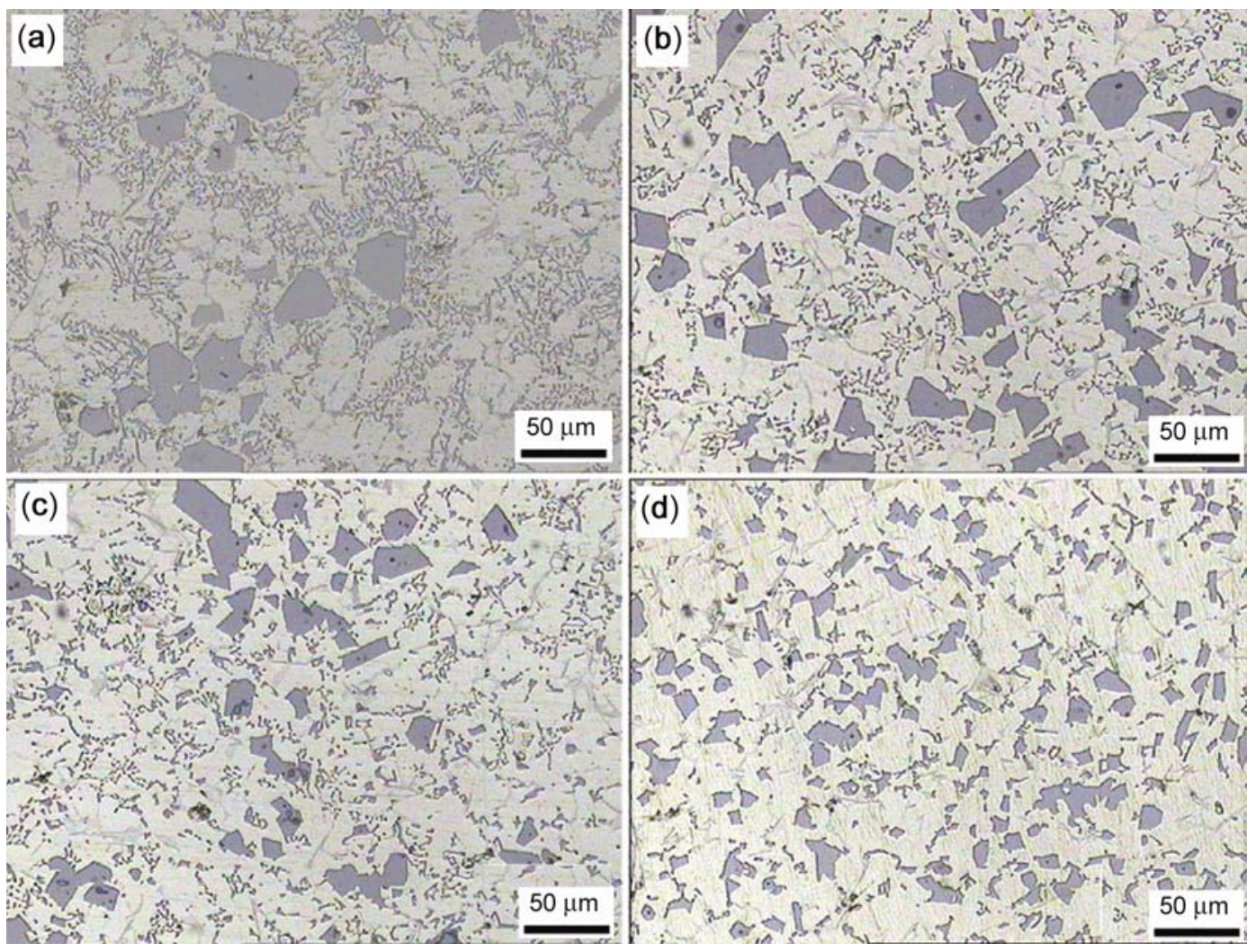

Figure 1. OM images showing the microstructural evolution of the hypereutectic Al-Si alloy processed under pressure of (a) 0, (b) $108 \cdot 6$, (c) 144.8 and (d) $181 \mathrm{MPa}$.

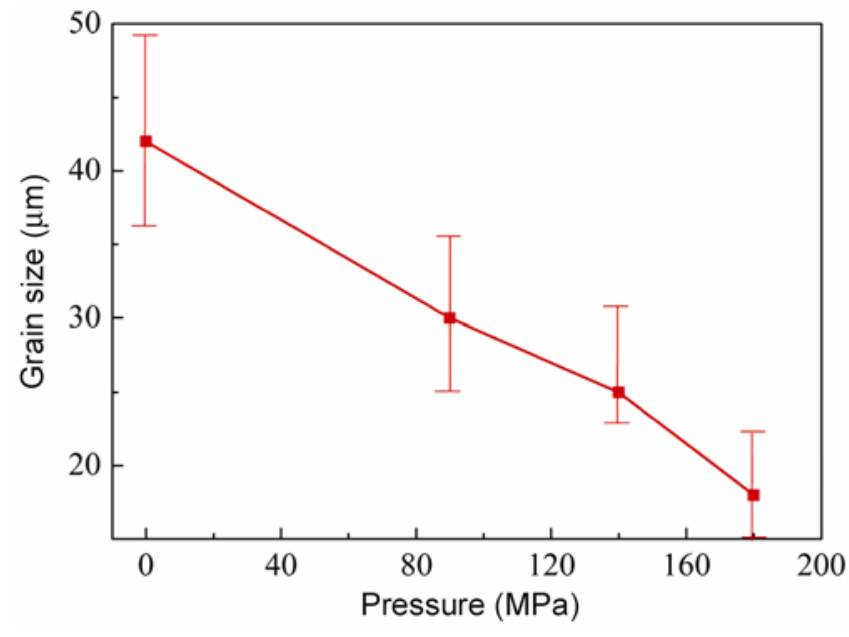

Figure 2. Evolution of grain size of the primary silicon for hypereutectic $\mathrm{Al}-\mathrm{Si}$ alloy under different liquid-die-forging pressures.

\subsection{Mechanical properties of the hypereutectic Al-Si alloy processed by liquid die forging}

Figure 3(a) displays the fracture strength and elongation of the hypereutectic Al-Si alloys processed by liquid die forging. It is evident that the fracture strength was increased significantly with the pressure increasing, as shown in figure 3(a). When the pressure was $0 \mathrm{MPa}$, the fracture strength and elongation were $185 \mathrm{MPa}$ and zero, respectively. However, when the pressure was increased to $180 \mathrm{MPa}$, the fracture strength was enhanced by $108.1 \%$ i.e. to $385 \mathrm{MPa}$, and the elongation was raised to $0.75 \%$. Similarly, the correspondent hardness was increased from HRB78 to HRB84 with the pressure increased from 90 to $180 \mathrm{MPa}$. These results show that the liquid die-forging pressure is effective to enhance the mechanical properties of the hypereutectic Al-Si alloy.

The mechanical properties of the hypereutectic Al-Si alloy mainly depend on the size and morphology of the primary $\mathrm{Si}$ and eutectic Si crystals. In hypereutectic $\mathrm{Al}-$ Si alloys, the cracks easily initiate from the hard and brittle primary Si (Choi et al 2012; Kilicaslana et al 2012). The cracks may also come from the debonding of Si particles, and then propagate through the boundaries with $\alpha$-Al phase (Chang et al 1998). The present results of tensile test show that the fracture strength and elongation of hypereutectic $\mathrm{Al}-\mathrm{Si}$ alloy were significantly improved by liquid die forging. This is because that the refinement of primary Si and eutectic Si can decrease or eliminate premature cracks initiation and fracture under tension.

Figure 4 presents the fractographs of the hypereutectic Al-Si alloy processed by liquid die forging. For the sample without liquid die forging (i.e. pressure is $0 \mathrm{MPa}$ ), the fracture surface was mainly characterized with cleavage 

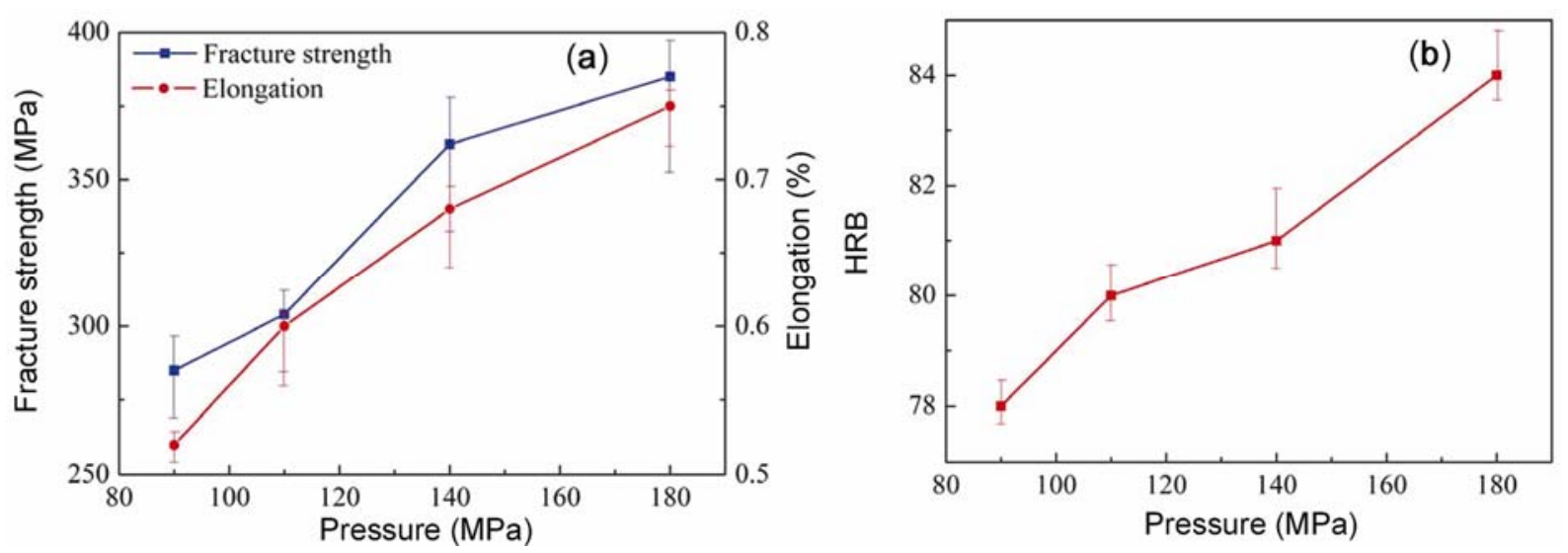

Figure 3. (a) Fracture strength and elongation and (b) Brinell hardness for liquid die-forged hypereutectic Al-Si alloy.
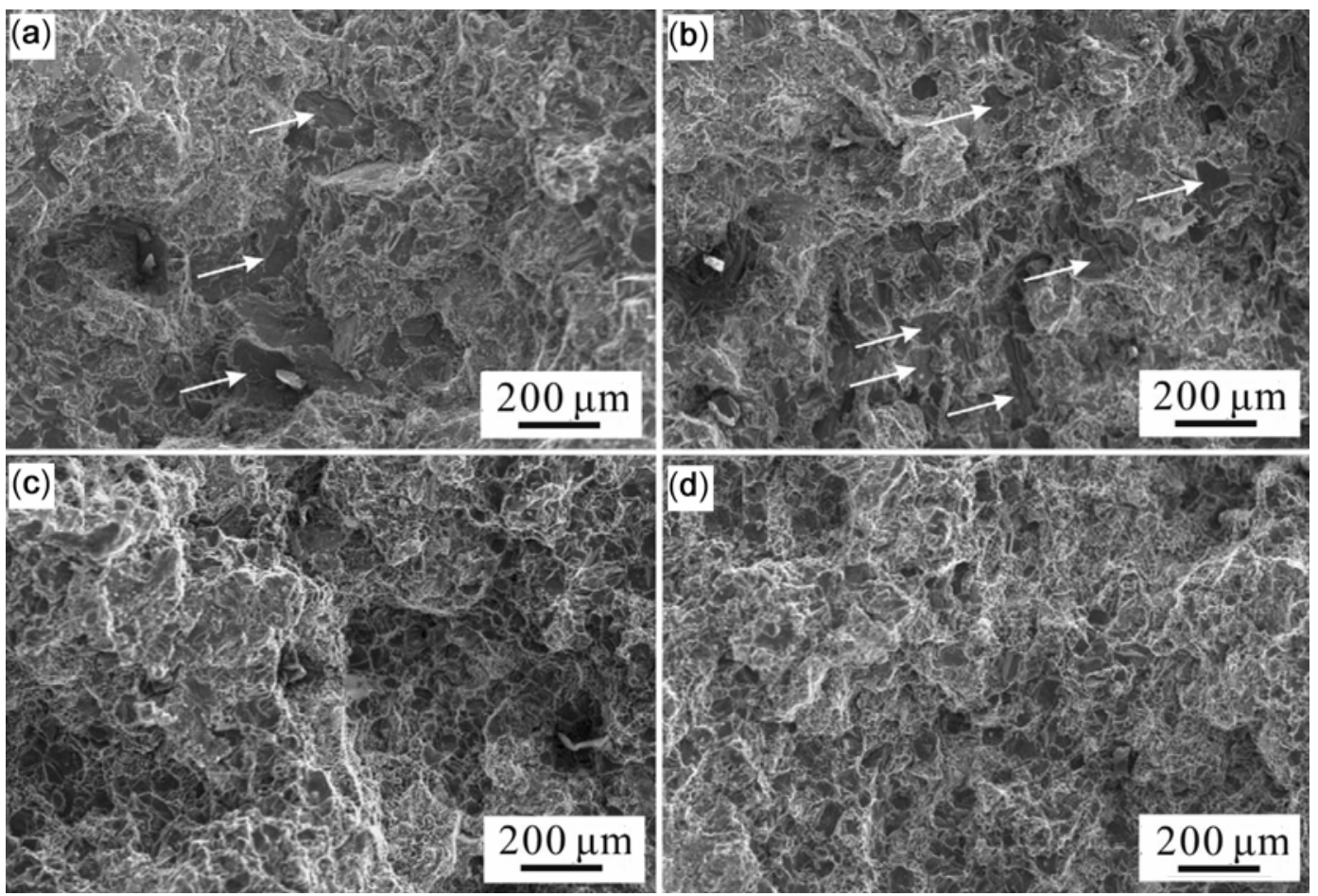

Figure 4. SEM images showing the tensile fracture features of the hypereutectic Al-Si alloy under different liquid die-forging pressures of (a) 90.5, (b) 108.6, (c) $144 \cdot 8$ and (d) $181 \mathrm{MPa}$.

planes and large crack sites in the primary Si phase, as shown in figure 4(a). When the pressure was increased up to 110 and $140 \mathrm{MPa}$, respectively, the fracture surfaces were covered by small crack planes in the refined primary Si phase and dimples in the eutectic matrix (figure 4(b and c)). Figure 4(d) shows the fractograph of the hypereutectic $\mathrm{Al}-\mathrm{Si}$ alloy processed with the pressure of $180 \mathrm{MPa}$. It is clear that many dimples were formed on the fracture surfaces. These results indicate that a transition from a brittle failure for the sample without liquid die forging to a ductile failure for the sample with liquid die forging.

The fracture of hypereutectic Al-Si alloys was mainly attributed to three factors (Zhou and Duszczyk 1990): (a) the size and distribution of the primary and eutectic Si crystals, (b) the bonding strength between the Si crystals and the eutectic matrix, and (c) the crack of the Si crystals. The present fracture morphology shows an intragranular failure mainly caused by the coarse primary $\mathrm{Si}$ crystals, and there are more cracks in the coarse primary $\mathrm{Si}$ than the finer primary $\mathrm{Si}$, as shown in figure 4 . With the load increasing, the flow stress increase in the matrix and lead to a stress concentration near the primary $\mathrm{Si}$ crystals under tensile testing. The primary $\mathrm{Si}$ will fracture, when the local tensile stress exceeds the intrinsic fracture stress of the primary $\mathrm{Si}$. In addition, cracks primarily initiate and propagate along the interfaces between primary Si crystals and Al matrix. When the neighbouring cracks 
link with each other, the fracture of the hypereutectic Al-Si alloys finally occurs (Xu et al 2007). In this work, the liquid die-forging pressure significantly decreased the size and changed the morphology of primary $\mathrm{Si}$ and eutectic Si crystals. Based on fracture mechanics (Mayers and Chawla 1999), the relation between the intrinsic fracture stress $\sigma_{\mathrm{F}}$ on the primary $\mathrm{Si}$ and the length $L$ of the internal defects can be expressed by

$$
\sigma_{\mathrm{F}}=\left(\frac{2 E \gamma}{\pi L}\right)^{1 / 2}
$$

Here $\gamma$ and $E$ are the fracture surface energy and the Young's modulus of the particles, respectively. According to (2), the internal defects of coarse primary Si crystals are much longer than fine $\mathrm{Si}$ crystals, which results in lowering the intrinsic fracture stress. Therefore, the refinement of the primary $\mathrm{Si}$ crystals can effectively enhance the tensile strength and the elongation of hypereutectic Al-Si alloy by liquid die forging.

\section{Conclusions}

In summary, the grain size of the primary $\mathrm{Si}$ in a hypereutectic Al-Si alloy was remarkably reduced by liquid die forging. By liquid die forging with pressure up to $180 \mathrm{MPa}$, the average size of the primary Si was reduced to be about $18 \mu \mathrm{m}$. The volume fraction of the eutectic silicon was also decreased with the increased pressure. The refinement of the microstructure significantly enhances the fracture strength and hardness of the hypereutectic Al-Si alloy.

\section{Acknowledgements}

This work was financially supported by the Education Department of Liaoning Province of China under Grant Nos 2009S053 and LT2010051.

\section{References}

Begg J 1992 Process optimization in the squeeze casting of zinc-aluminum alloys and composites (UK: Loughborough University of Technology)

Brazhkina V V, Popov S V, Voloshina R N, Stanev L M and Spirov I G 1991 High Press. Res. 6333

Chang J Y, Moon I and Choi C S 1998 J. Mater. Sci. 335015

Chen Z W, Jie W Q and Zhang R J 2005 Mater. Lett. 5992183

Choi H S, Konishi H and Li X C 2012 Mater. Sci. Eng. A541 159

Choi H S and Li X C 2012 J. Mater. Sci. 473096

Dahle A K, Nogita K, McDonald S D, Dinnis C and Lu L 2005 Mater. Sci. Eng. A413-414 243

Hekmat-Ardakan A and Ajersch F 2010 Acta Mater. 583422

Hekmat-Ardakan A, Liu X C, Ajersch F and Chen X G 2010 Wear 269684
Hong S Z and Zeng Z P 2002 Spec. Cast. Nonferr. Alloys 22 26

Jung H K, Seo P K and Kang C G 2001 J. Mater. Process. Technol. 113568

Kilicaslana M F, Lee W R, Lee T H, Sohn Y H and Hong S J 2012 Mater. Lett. 71164

Li B, Wang H W, Jie J C and Wei Z J 2011a Mater. Des. 32 1617

Li B, Wang H W, Jie J C and Wei Z J 2011b J. Alloys Compd. 5093387

Li L X, Zong H T, Li M, Wang H X and Cai H X 2012 High Temp.-High Pres. 4169

Liu G, Li G D, Cai A H and Chen Z K 2011 Mater. Des. 32121

Lu D H, Jiang Y H, Guan G S, Zhou R F, Li Z H and Zhou R 2007 J. Mater. Process. Technol. 18913

Lu L, Nogita K and Dahle A K 2005 Mater. Sci. Eng. A399 244

Mayers M A and Chawla K K 1999 Mechanical behaviour of materials (Upper Saddle River, New Jersey: Prentice Hall)

McDonald S D, Nogita K and Dahle A K 2004 Acta Mater. 52 4273

Mohamed A M A, Samuel A M, Samuel F H and Doty H W 2009 Mater. Des. 303943

Murali S and Yong M S 2010 J. Mater. Process. Technol. 210 1276

Nogita K, Yasuda H, Yoshida M, McDonald S D, Uesugi K, Takeuchi A and Suzuki Y 2010 J. Alloys Compd. 489415

Prukkanona W, Srisukhumbowornchai N and Limmaneevichitr C 2009 J. Alloys Compd. 477454

Sha M, Wu S S, Wang X T, Wan L and Ping A 2012 Mater. Sci. Eng. A535 258

Song K K, Bian X F, Guo J, Wang S H, Sun B A, Li X L and Wang C D 2007 J. Alloys Compd. 440 L8

Srirangam P, Kramer M J and Shankar S 2011 Acta Mater. 59 503

Tsai Y C, Chou C Y, Lee S L, Lin C K, Lin J C and Lim S W 2009 J. Alloys Compd. 487157

Uzun O, Karaaslan T, Gogebakan M and Keskin M 2004 J. Alloys Compd. 376149

Vončina M, Kores S, Mrvar P and Medved J 2011 J. Alloys Compd. 5097349

Wang E D, Hui X D, Wang S S, Zhao Y F and Chen G L 2011 Mater. Sci. Eng. A528 5764

Wang Y P, Wang S J, Li H and Liu X F 2009 J. Alloys Compd. 477139

Wu H and Chin B A 1991 J. Mater. Sci. 26993

Xing P F, Gao B, Zhuang Y X, Liu K H and Tu G F 2010a J. Rare Earths 28927

Xing P F, Gao B, Zhuang Y X, Liu K H and Tu G F 2010b Acta Metall. Sin. 23327

Xu C L, Wang H Y, Yang Y F and Jiang Q C 2007 Mater. Sci. Eng. A452-453 341

Yi H K and Zhang D 2003 Mater. Lett. 572523

Yu X F, Zhang G Z, Wang X Y, Gao Y Y, Jia G L and Hao Z Y 1999 J. Mater. Sci. 344149

Yu X F, Zhang G Z, Xiao H J, Pan A S, Jia G L, Gao Y Y, Hao Z Y and Guo X B 2000 Chin. J. Mater. Res. 14141

Zhang H H, Duan H L, Shao G J, Xu L P, Yin J L and Yan B 2006 Rare Metals 2511

Zhou J and Duszczyk J 1990 J. Mater. Sci. 254541 